\title{
NEW NIOBIUM CAPACITORS WITH STABLE ELECTRICAL PARAMETERS*
}

\author{
H. ZILLGEN ${ }^{\dagger}$, M. STENZEL and W. LOHWASSER \\ EPCOS AG, Capacitor Division, K O T E P.O. BOX 1840, D-89508 Heidenheim, Germany
}

(Received December 2001)

\begin{abstract}
The replacement of the anode material in tantalum capacitors by a new generation of high CV niobium powders offers the possibility to get an economical alternative to tantalum for a wide range of applications. Due to the high CV potential of niobium powder there is also an alternative to low voltage aluminum electrolytic capacitors. We developed a new niobium capacitor which shows stable electrical values. By optimizing the structure of the dielectric and the cathodic layers as well as the process parameters we gained a capacitor which can be used up to $105^{\circ} \mathrm{C}$. Electrical characteristics and lifetest behavior of niobium capacitors out of $100 \mathrm{k}-150 \mathrm{k} \mathrm{CV} / \mathrm{g}$ powder will be discussed.
\end{abstract}

Keywords: Niobium capacitors, Niobium powders

\section{INTRODUCTION}

One of the big advantages of tantalum capacitors is the high specific capacitance. Especially in the last years the tremendous development of high CV-values in all SMD case sizes have been one of the driving forces of the booming business for tantalum capacitors. Its properties fitted perfectly to the strong growing demand of high $\mathrm{CV}$-values for handheld applications like e.g. mobile phones. High CV tantalum capacitors are also of interest in the power sections of EDP (electronic data processing) applications, especially for all applications which are limited in space, like hard disk drives, laptops or all kinds of PDA's (personal digital assistant).

In the near future, for sure, mobile communication and EDP applications will increasingly merge together. Fast internet access via ADSL or high mobile data transfer rates by using GPRS or UMTS are one of the key applications in the future for high CV tantalum capacitors, underlining this trend. Therefore the growing demand for high $\mathrm{CV}$ capacitors will still continue and even request a faster response to the market.

A major role for high $\mathrm{CV}$ tantalum capacitors played the development of the tantalum powder. Since the dielectric constant of $\mathrm{Ta}_{2} \mathrm{O}_{5}$, the dielectric layer of tantalum capacitors,

\footnotetext{
* An earlier version of this paper was published in the Proceedings of the 15th Annual European Passive Components Conference (CARTS-EUROPE 2001), 15-19 October 2001, pp. 149-152.

$\dagger$ Corresponding author. Tel.: + 497321 326-619; Fax: + 497321 326-88619; E-mail: holger.zillgen@epcos.com
} 


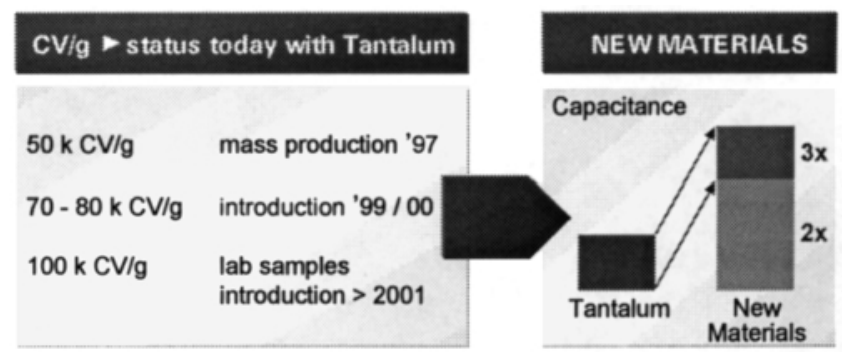

FIGURE 1 Status of powder development for tantalum capacitors and outlook for capacitors with new anode materials.

is fixed, the only key to increase the CV class is the morphology of the powder. The step of sodium reduction of the "K-salt" $\left(\mathrm{K}_{2} \mathrm{TaF}_{7}\right)$, an intermediate product in processing capacitor grade tantalum powder, was the key in the development obtaining a finer morphology and offering a higher surface area in order to increase the specific CV value of the tantalum powder. Receiving the $100 \mathrm{k} \mathrm{CV} / \mathrm{g}$ powder class it seems to be scratching the limits, at least, for the routing via the sodium reduction process. Another possibility to increase the capacitance is to exchange the base material. Niobium is the most promising material with this regard (see Fig. 1).

Belonging to the same group of the periodic system of elements, its chemical properties are very similar to tantalum. Niobium forms also a pentoxide $\left(\mathrm{Nb}_{2} \mathrm{O}_{5}\right)$, but with a dielectric constant of 41 , compared to the $\varepsilon=27$ for $\mathrm{Ta}_{2} \mathrm{O}_{5}$. Introducing niobium will therefore increase the CV development for "tantalum capacitors" significantly (see Fig. 2).

Niobium capacitors will be processed in a very similar way as tantalum capacitors, means pressing of porous pellets out of capacitor grade powder, sintering and applying anodic oxidation to form the dielectric niobiumpentoxide (preforming). The $\mathrm{MnO}_{2}$ counterelectrode and the outer contact layer will be processed very similar to the known process for tantalum capacitors, and, accordingly, the assembly and finishing will be following mainly the tantalum process.

Besides the niobiumpentoxide, niobium forms also suboxides during the preforming process, like $\mathrm{NbO}$ and $\mathrm{NbO}_{2}$ which are metallic conducting and semiconducting and partly

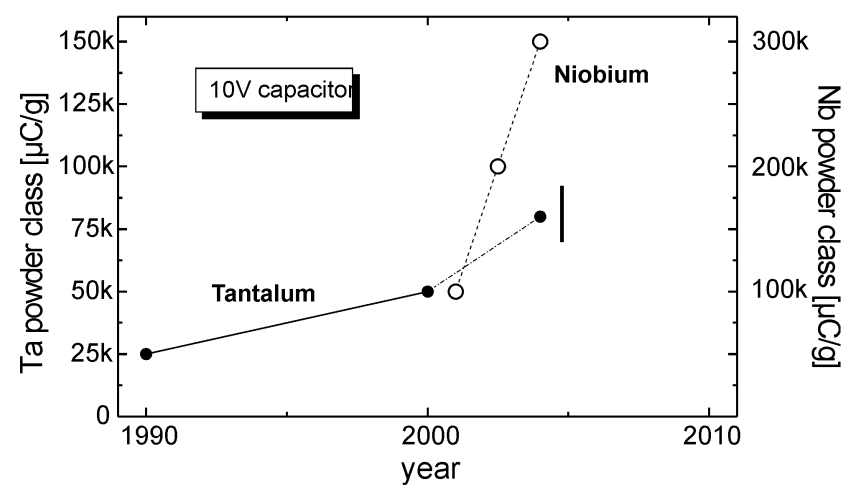

FIGURE 2 Capacitor powder development within the last years and outlook for the near future. 
present in the niobiumoxide system. Creating potential pathways for leakage current, this influence by these suboxides must be solved. The next section shows results of niobium capacitors, achieved by implementations of process adjustments and more sophisticated powder developments in order to overcome these influences.

\section{ELECTRICAL PARAMETERS}

Although there are some difficulties related to Niobium, we were able to build a capacitor with stable electrical parameters. We focused our interest mainly on the suboxides. In addition to the $\mathrm{Nb}_{2} \mathrm{O}_{5}$ (the "real" dielectric), suboxides such as $\mathrm{NbO}$ and $\mathrm{NbO}_{2}$ are partly present in a niobium oxide system. These suboxides, one of them metallic conducting, the other one semiconducting, don't exist in a tantalum dielectric. This leads to a potential risk of higher leakage current or even failures in a capacitor. The higher oxygen solubility in niobium, as compared to tantalum, further supports the forming of suboxides in a niobium/niobium oxide layer system, especially at elevated temperatures.

Thus the aims of the development of niobium capacitors are to overcome the forming of suboxides and also to stabilize the dielectric layer.

Two approaches will meet this challenge. With more sophisticated powder development and process adjustments in the manufacturing of niobium capacitors, the deterioration of the dielectric layer can be avoided. Not only an adjustment of process parameters was necessary, but great exertions to find some additional process steps. EPCOS has exerted tremendous efforts on all of these fronts - and we gained a niobium capacitor with stable electrical parameters.

In Figure 3, the temperature behavior of the capacity is compared to tantalum, ceramic and aluminum capacitor technology. The niobium capacitor demonstrates its recognized and stable behavior similar to the tantalum based on the chemical relationship between tantalum and niobium. Between $-55^{\circ} \mathrm{C}$ and $125^{\circ} \mathrm{C}$, the drift range for niobium capacitors is below $\pm 20 \%$, while ceramic capacitors loose up to $80 \%$ of the nominal capacitance. Similar to the tantalums, the counterelectrode of the niobium capacitors is $\mathrm{MnO}_{2}$, created by

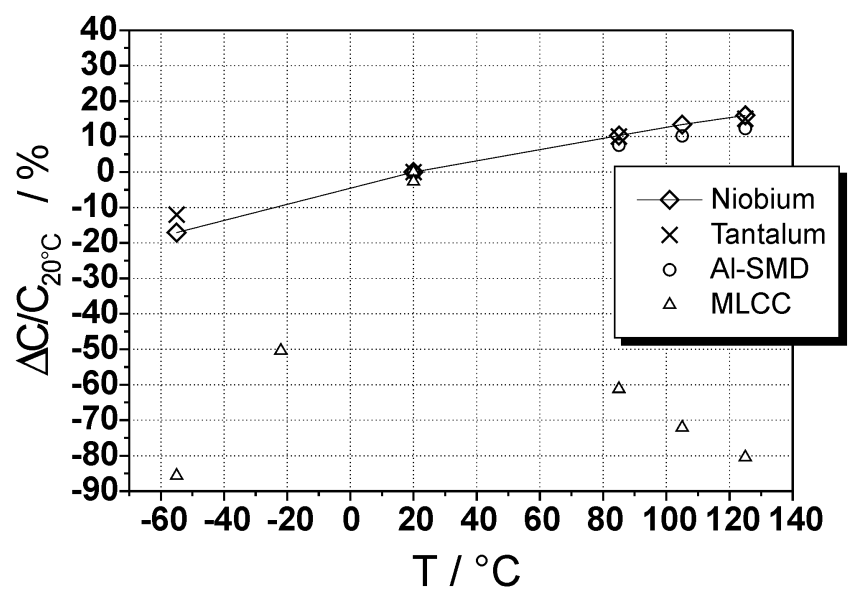

FIGURE 3 Temperature dependence of the capacitance for niobium $(100 \mu \mathrm{F} / 10 \mathrm{~V})$, tantalum $(100 \mu \mathrm{F} / 10 \mathrm{~V})$, aluminum $(47 \mu \mathrm{F} / 10 \mathrm{~V}) \mathrm{SMD}$ and ceramic $(47 \mu \mathrm{F} / 6.3 \mathrm{~V})$ capacitor technology. 
impregnation of the sintered and formed anodes in manganese nitrate and a subsequent pyrolysis to become the solid manganese oxide $\mathrm{MnO}_{2}$.

Although the pyrolysis temperature is rather high for the niobium oxide, which is more sensitive to temperature than tantalum oxide, EPCOS was successful in stabilizing the niobium/niobium oxide system to withstand this process step.

The ESR is dominated by the counterelectrode. Thus it is not surprising that the ESR behavior versus frequency of the niobium capacitors is almost identical to that of tantalum capacitors (Fig. 4). By continuos optimization of the cathodic layers there is no doubt it will reach the ESR performance of the tantalum capacitors.

Figure 5 shows the frequency dependence of the capacitance. As expected there is no great difference between the niobium and the tantalum capacitor. The better stability of the capacitance for the ceramic capacitor can be explained by the better ESR values.

The stability of niobium capacitors to inrush voltage is as good as that of tantalum capacitors. Figure 6 shows the result of surge step stress tests for a $100 \mu \mathrm{F} / 10 \mathrm{~V}$ Chip D Niobium capacitor. The capacitor was stressed with five short pulses at a series resistance of $0.5 \Omega$.
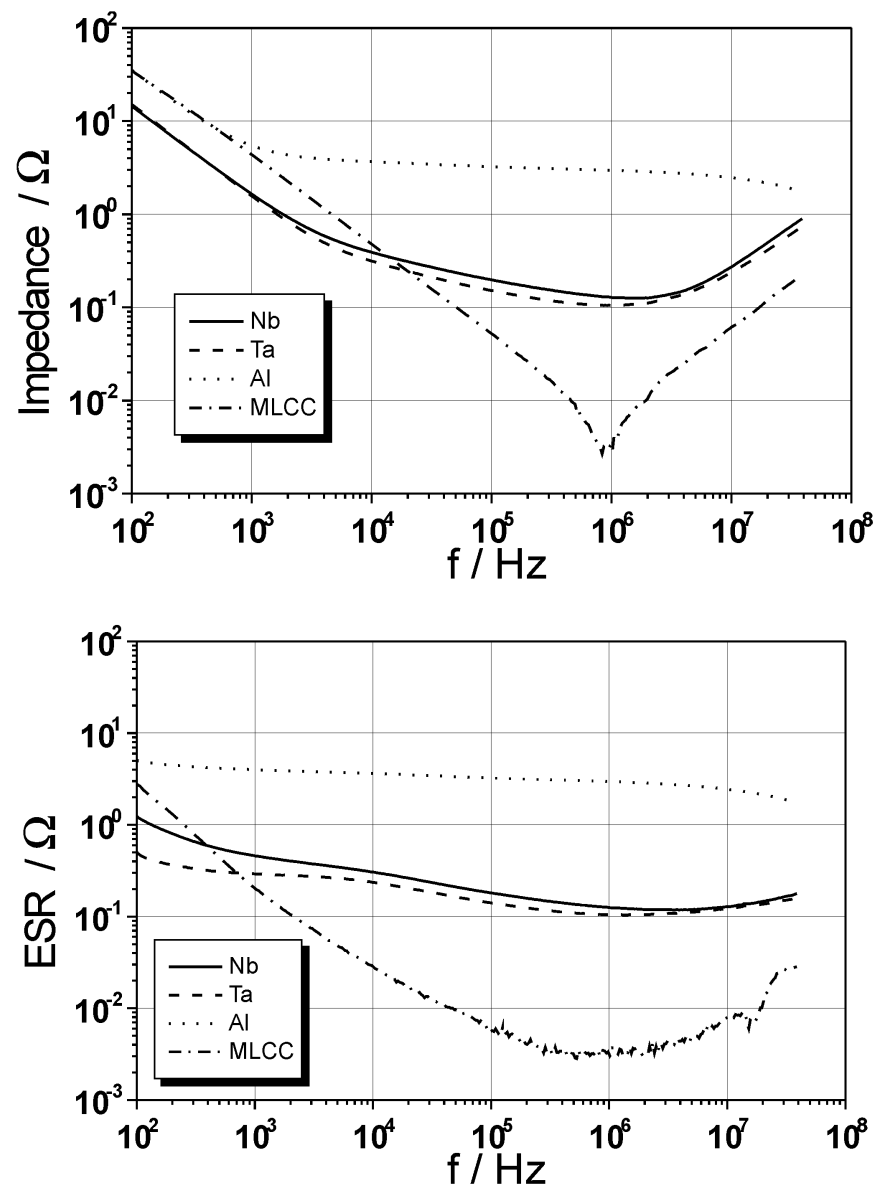

FIGURE 4 Frequency dependence of the impedance and the ESR for niobium, tantalum, aluminum SMD and ceramic capacitor technology. 


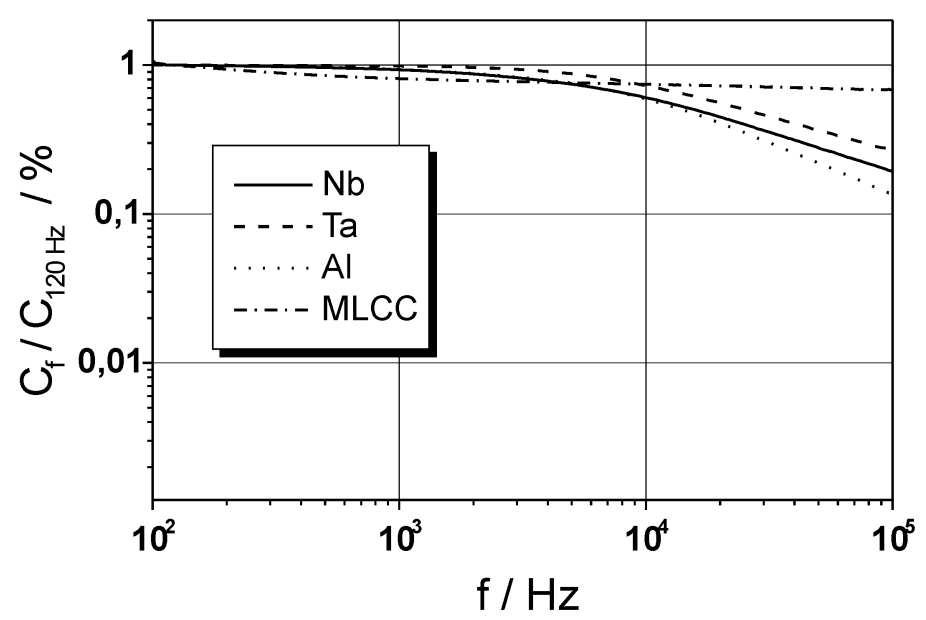

FIGURE 6 Surge step stress test: breakdown voltage of a $100 \mu \mathrm{F} / 10 \mathrm{~V}$ chip D niobium capacitor.

Beginning at rated voltage, the voltage was raised stepwise. The maximum of the distribution is at $28 \mathrm{~V}$ and no capacitor with rated voltage of $10 \mathrm{~V}$ failed at voltages lower than $21 \mathrm{~V}$.

Niobium capacitors show a higher DC leakage current - a maximum of two-to-four times that of tantalum capacitors. For most applications this is not a problem, because the maximum current usually will remain far below $50 \mu \mathrm{A}$ for such capacitors. Compared with the entire power consumption of micro processors in PC applications, for example, these values are small and thus not significant. So, it's no problem to use niobium capacitors in a wide range of applications.

The more important question is the reliability of niobium technology. As demonstrated in life tests (Fig. 7) the capacitance is stable and the DC leakage current increases over time, but the increase diminishes and saturation occurs. We are testing even niobium capacitors with modified powder and a modified production process and they showed in first results less increase and lower DCL-values in life tests.

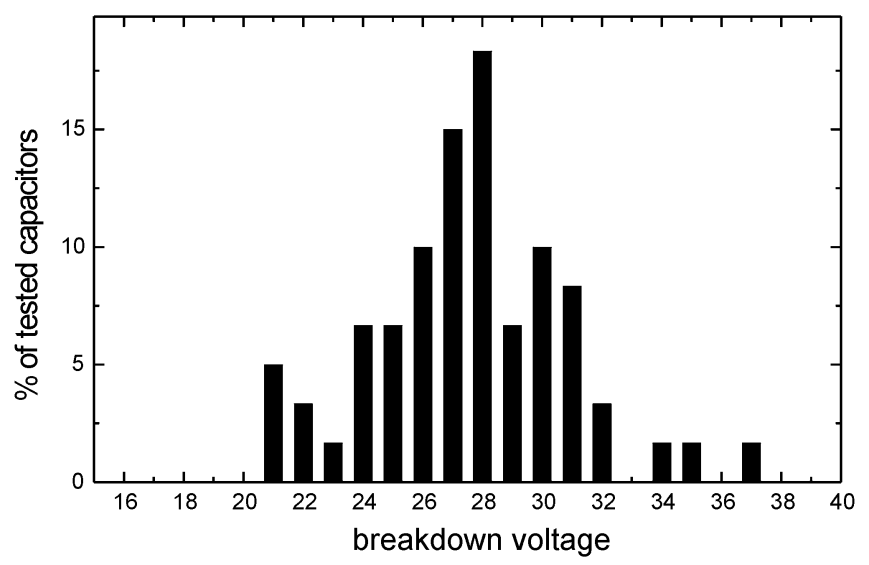

FIGURE 5 Frequency dependence of the capacitance for different capacitor technologies. 

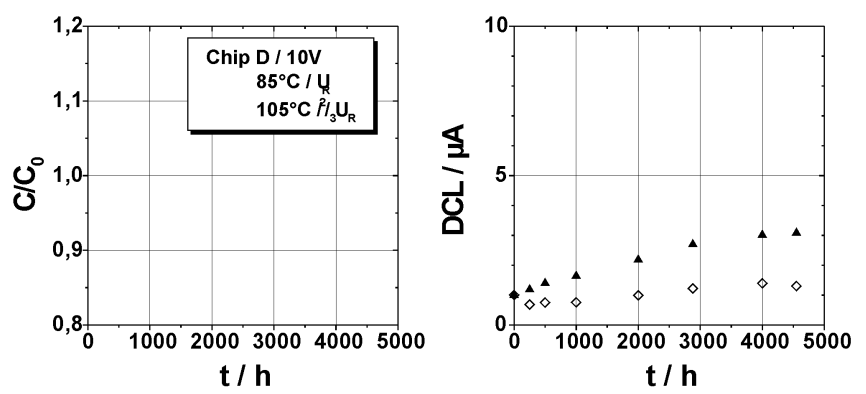

FIGURE 7 Life tests of a $10 \mathrm{~V}$ chip D niobium capacitor: $85^{\circ} \mathrm{C}$, rated voltage $U_{R}$ and $105^{\circ} \mathrm{C}, 2 / 3 U_{R}$; capacitance and leakage current for several thousand hours.

\section{SUMMARY AND OUTLOOK}

By replacing the anode material in tantalum capacitors by a high CV niobium powder and by developing a new and stable manufacturing process, a new niobium capacitor with stable electrical parameters was developed.

This new capacitors will be able to operate between $-55^{\circ} \mathrm{C}$ and $+105^{\circ} \mathrm{C}$. The voltage range of $4 \mathrm{~V}$ to $10 \mathrm{~V}$ will serve a great part of applications. According to initial results, similar design rules to tantalum capacitors are valid. Above $85{ }^{\circ} \mathrm{C}$, a derating down to two-thirds of the rated voltage is complementary; for use under surge conditions, a derating factor of two is recommended, in order to obtain a low failure rate.

Even if the $100 \mathrm{k}$ niobium powder currently available does not yet offer a big advantage with regard to the highest $\mathrm{CV}$ values of tantalum, the manufacturing technology for niobium powders and niobium capacitors will be further developed, to achieve higher CV-values, to lower the overall leakage current level, to extend the voltage range to $16 \mathrm{~V}$ and to extend the temperature range up to $125^{\circ} \mathrm{C}$. Recent results for achieving stable and reliable niobium capacitors with these extended characteristics are very promising.

Starting with the niobium capacitor, we began to combine this capacitor with other technologies, like multianode and polymer capacitor. Figure 8 shows the ESR and the capacitance of tantalum and niobium capacitors for today and visions for tomorrow. One way to reduce ESR values (upper left of Fig. 8) is to use a polymer layer instead of a cathode of manganese dioxide. The ESR of a polymer capacitor is only a third of that of a standard tantalum capacitor produced by manganese dioxide deposition. The use of niobium as anode material will allow higher CV values. Combining these two technologies we will gain a high capacitance with a low ESR, which is ideal for a wide range of applications.

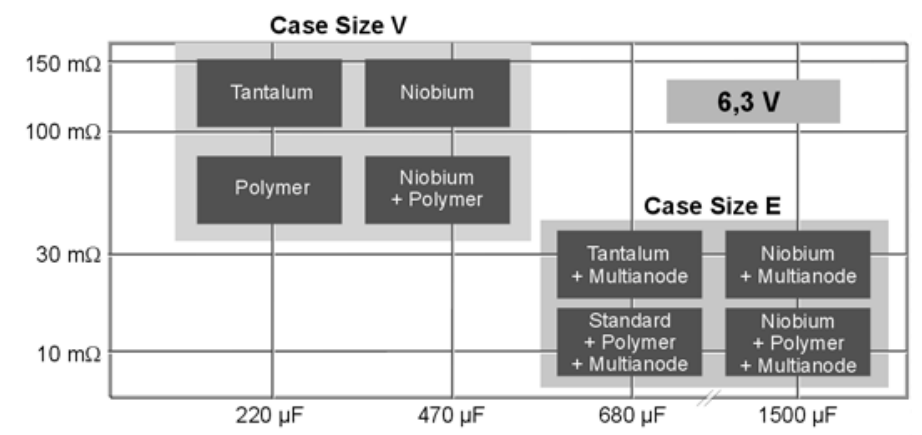

FIGURE 8 ESR and capacitance of tantalum and niobium capacitors: today and in future. 
Another way of combining new technologies is the use of niobium and/or polymer in a multianode capacitor. The use of multianodes allows to reduce the ESR to a third: a single-digit ESR will become reality.

And how will a capacitor in the future look like? A niobium capacitor with a polymer cathode manufactured in multianode technology is conceivable.

Although the standard tantalum capacitor will not completely be replaced by niobium capacitors and new technologies, it is both, necessary and appropriate, to widen their range. Niobium capacitors will soon find their applications and will gain market share. 

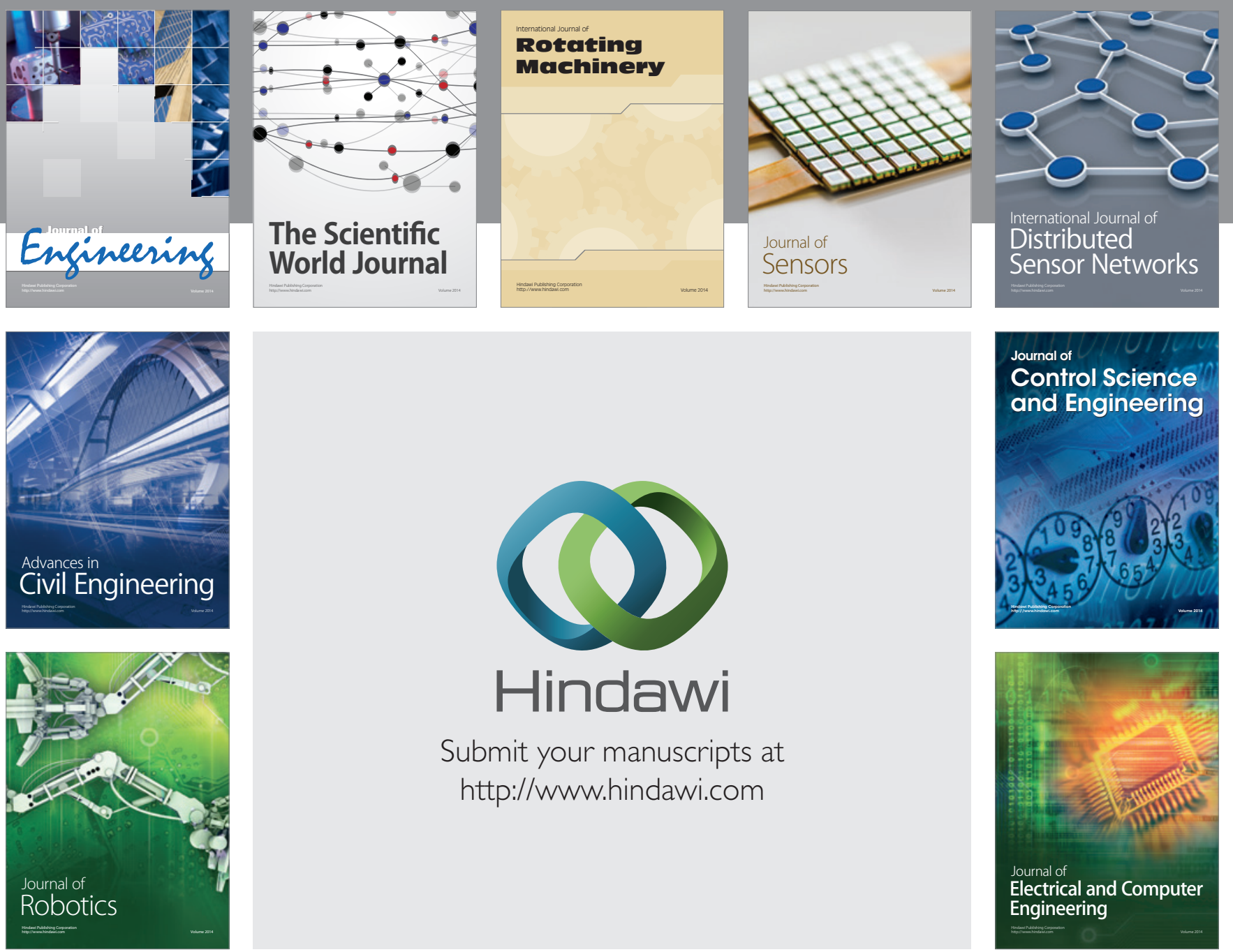

Submit your manuscripts at

http://www.hindawi.com
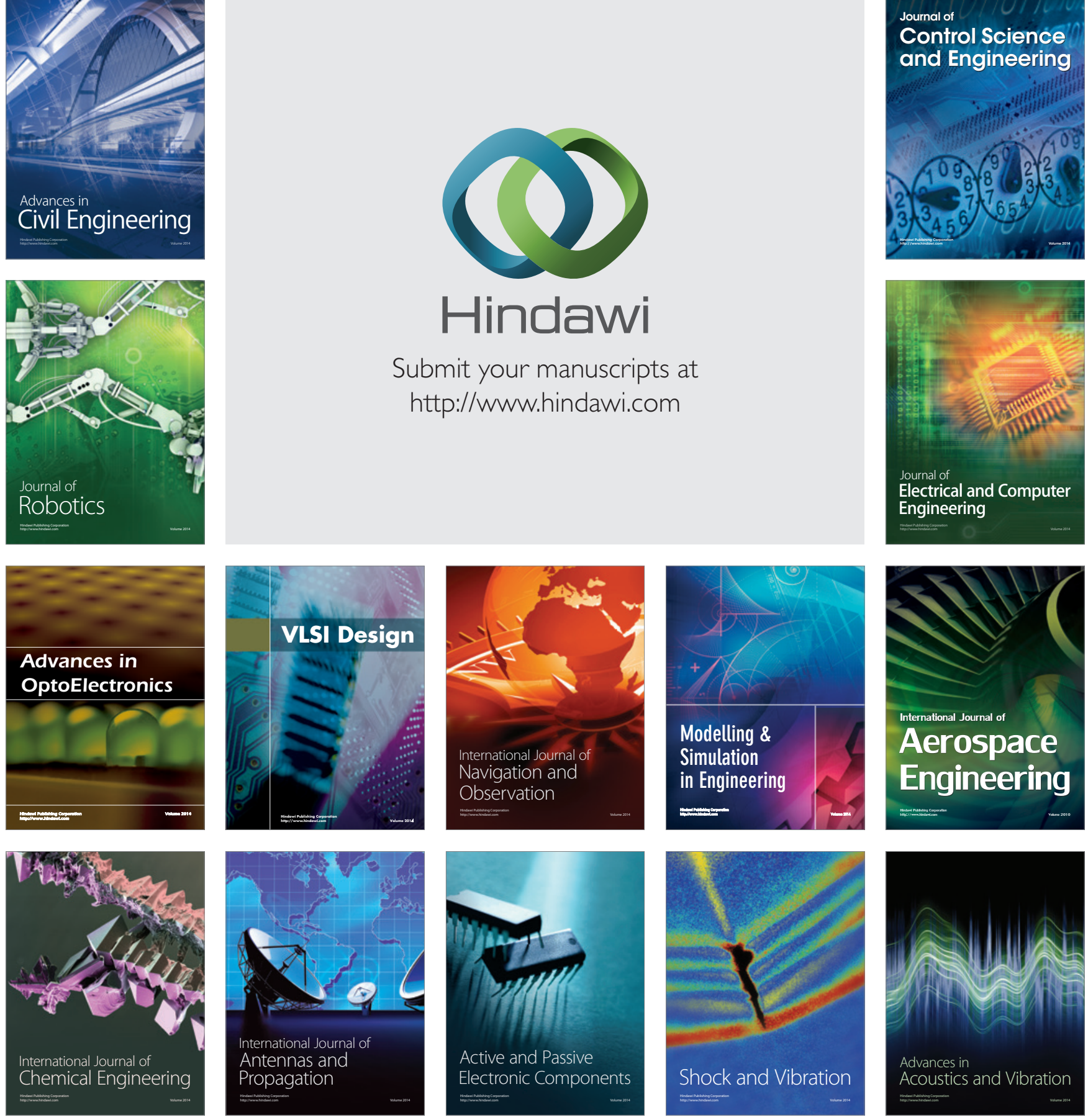